\title{
The effect of providing educational sessions about sexually transmitted diseases on knowledge and attitudes of secondary school students at Zagazig City
}

\author{
Samia Farouk Mahmoud ${ }^{1}$, Naeima Mohamed El-Sayed Ahmed*2 \\ ${ }^{1}$ Community Health Nursing Department, Faculty of Nursing, Zagazig University, Zagazig, Egypt \\ ${ }^{2}$ Obstetrics and Gynecological Nursing Department, Faculty of Nursing, Zagazig University, Zagazig, Egypt
}

Received: June 23, 2017

DOI: $10.5430 /$ jnep.v8n4p16

\author{
Accepted: November 8, 2017 \\ Online Published: November 26, 2017
}

URL: https://doi.org/10.5430/jnep.v8n4p16

\begin{abstract}
Background and objective: Sexually Transmitted Diseases are a major health problem that affects mostly young people. The aim of the study was to assess the effect of providing educational sessions about Sexually Transmitted Diseases on knowledge and attitude of secondary school students.

Methods: A quasi-experimental research design was used in carrying out the study. The study was conducted at four governmental public secondary schools in Zagazig City, 367 secondary school students from the previously mentioned settings were included in the study. Two tools were used to collect necessary data: Tools (I): An interview questionnaire sheet; It was consisted of two parts: Part (A) entailed questions pertaining to socio demographic characteristics of the students, while part (B) included questions regarding student's knowledge about sexually transmitted diseases. Tool (II): It was intended to assess student's attitude toward sexually transmitted diseases.

Results: Pre, post and follow up students' knowledge and attitude tests after sessions implementation revealed highly statistically significant improvement in students' knowledge and attitudes $(p<.001)$, which justified the research hypothesis.

Conclusions: The educational sessions significantly brought out improvements in the knowledge and attitudes of adolescent students regarding sexually transmitted diseases. The study recommended an educational program about all types of sexually transmitted diseases to be included into the secondary school curriculum and media enlightenment campaigns about these diseases should also be emphasized.
\end{abstract}

Key Words: Adolescents secondary school, Educational sessions, Sexually transmitted diseases

\section{INTRODUCTION}

The major human resource for the development of any nation is the energy and creativity of a healthy young-adult population. Health in general, sexual and reproductive health in particular, refers not only to an absence of disease but also to physical, mental, and social wellbeing. ${ }^{[1]}$ The stage of life during which individuals reach sexual maturity is known as adolescence. It is a crucial period of life, a bridge between childhood and adulthood. ${ }^{[2]}$ The World Health Organization identifies it as the age range 10-19 years. In Egypt adolescents constitute $19.1 \%$ of the total Egyptian population. ${ }^{[3]}$

Although the change is biological, the duration and nature of adolescence are primarily a social construct and thus vary greatly from culture to culture. It is a period of increased

\footnotetext{
${ }^{*}$ Correspondence: Naeima Mohamed El-Sayed Ahmed; Email: dr_naima2002@yahoo.com; Address: Faculty of Nursing, Zagazig University, Zagazig, Egypt.
} 
risk taking; these people are vulnerable to sexually transmitted diseases (STDs) and Human Immunodeficiency Virus (HIV). However, little attention is paid for these populations and majority of adolescents still do not have access to information and education on sexuality, reproduction health and rights. ${ }^{[4]}$ Additionally, adolescent sexual and reproductive health education is still a neglected issue in many countries, especially the adolescents from the rural part of the developing countries due to unavailability of reproductive health care services and trainings. ${ }^{[5]}$

Sexually Transmitted Diseases are a major health problem that affects mostly young people, not only in developing but also in developed countries. ${ }^{[6]}$ It refers to a variety of clinical syndromes and infections caused by pathogens that can be acquired and transmitted through sexual activity from one person to another. ${ }^{[7]}$ Bacterial infections like chlamydia, syphilis and gonorrhea while viral infections as human papilloma virus (HPV), herpes simplex and HIV. The infection can be spread through oral, vaginal and anal sex, or through sharing, using unsterilized needles and contact with blood. Transmission can also occur through direct contact with affected body parts, tissue and body fluids of infected persons, vertical transmission occur where the mother passes the infection to her child in utero or during childbirth. ${ }^{[8]}$

Many people with STDs are asymptomatic and remain undiagnosed. In addition, those who are diagnosed are frequently not reported and counted. Furthermore, most of the published data on the prevalence and incidence of STDs come from developed countries. So, untreated or poorly treated STDs are associated with a lot of complications. ${ }^{[9]}$ In males, gonorrhea as well as chlamydia trachomatis infection causes epididymitis which can result in infertility in the future, in addition to, inflammatory urethral stricture which may lead to urinary retention and possibly chronic renal failure if not properly managed. For the females, pelvic inflammatory disease, dyspareunia, infertility, chronic pelvic pain, increased risk of ectopic pregnancies, abortions, stillbirths, and perinatal and neonatal morbidities can occur, jeopardizing their future reproductive competences. Additionally, persistent HPV infections can cause cervical and other forms of cancer and genital warts. ${ }^{[10]}$

Insufficient knowledge about sexually transmitted diseases and issues around accessing health services are among the major impediments to successfully prevent STDs among adolescent populations in developing countries. ${ }^{[11]}$

Health educators in the region should play a leading role in educating the population about prevention from STDs and put it into the public consciousness. Moreover, the primary prevention of sexually transmitted diseases needs to be given high priority and education, it should be addressed early in schools to encourage premarital screenings and hence help reduce the risk of the possible expansion of infection. ${ }^{[2]}$ Additionally, female adolescents and young women are more vulnerable than men to infection with STDs and to its complications because of the greater mucosal surface exposed to a greater quantity of pathogens during sexual intercourse. ${ }^{[9]}$

Nurses cannot ignore the care of patients' sexual health needs and they have an important role in caring and risk assessment of patients with STDs through a conduct of physical examinations, determination of medical and personal histories of patients and providing treatment. Additionally, the STDs nurse also instructs and counsel patients in the area of sexually transmitted diseases. ${ }^{[12]}$

\subsection{Significance of the study}

In Egyptian society, discussing STDs is considered taboo where ethics and social factors give rise to many obstacles. On other hand, the available information on STDs epidemiological status is limited and can't quantify the situation, guide sessions planning or assess the impact of interventions. The STDs epidemiological data are largely driven from fragmented researches focusing chiefly on HIV related aspects, with negligence of other STDs, on other hand, the prevalence and incidence of STDs in Egypt have remained mostly unknown, and its impact on public health was largely undetermined. ${ }^{[13]}$ Sex education aims to reduce the risks of potentially negative outcome from sexual behavior such as fear and STDs including HIV. Therefore, effective sexual and reproductive awareness sessions should start early before young people reach puberty more so before they have developed established patterns of behavior. So, providing relevant information's about STDs and providing a positive attitude regarding it, is a highly desirable and effective intervention in the prevention and control of the disease.

\subsection{Aim of the study}

The aim of this study was to assess the effect of providing educational sessions about Sexually Transmitted Diseases on knowledge and attitudes of secondary school students at Zagazig City. This was accomplished through:

(1) Assessing the students' knowledge and attitude regarding STDs prior and after the educational session's intervention.

(2) Designing and implementing health educational sessions bout STDs.

(3) Evaluating the effectiveness of health educational sessions bout STDs on knowledge and attitudes of students. 


\subsection{Research hypothesis}

After implementation of educational sessions the students' knowledge and attitudes related to sexual transmitted diseases will be improved.

\section{SUBJECTS AND METHODS}

\subsection{Research design}

A quasi-experimental design (pre and post intervention) was utilized to fulfill the aim of this study.

\subsection{Setting}

A list of all governmental public secondary schools at Zagazig City was prepared by the Directory of Education. Four governmental public secondary schools were chosen randomly from the list of (nine schools) to represent different sectors of Zagazig City, two schools from East Educational Administration and two schools from West Educational Administration, these were namely: (Gamal Abd-El Naser, ElSayeda Khadiga Secondary School for Girls, El-Sadat Secondary School for Boys and Zagazig Secondary School for Boys).

\subsection{Sample}

Students recruited from the above mentioned settings at the time of the data collection were included in the study with a total number of 367 students; who met the inclusion criteria, both sexes (boys \& girls), second grade and accept to participate in the study. They were divided into El-Sayeda Khadiga Secondary School for Girls, El-Sadat Secondary School for Boys, Zagazig Secondary School for Boys, 100 students from each of the three mentioned schools and Gamal Abd-El Naser 67 students. A list of all classes in the grade 2 of each secondary school was obtained from the headmaster of each school and was chosen randomly. The total capacity of each class ranged between 38 to 45 students and the actual presentations of the students ranged between 20 to 30 students and the students of the study were also chosen randomly.

\subsection{Sample size}

The sample size was performed using the Epi-Info package version 6.01 relaying on: total number of students in grade 2 at the randomly selected four secondary schools $(n=3,042)$ and a prevalence of rate of knowledge on STDs $42.3 \%$. [14] Application of the test depended on confidence interval 95\% confidence and power $80 \%$. The sample size was calculated to be 126 , dropout rate must be considered also $10 \%$. So, the sample size should be 140 students. The sample was increased to 376 to compensate for an expected dropout rate of $10 \%$.

\subsection{Tools of data collection}

Two tools developed by the researchers, based on current related literature were used to collect the necessary data for achieving the study objectives:

Tool (I): A self-administered questionnaire. It consisted of two parts:

Part A: For collecting data pertaining to socio demographic characteristics of the students such as: age, residence (rural/urban), education of their parents, number of family members and monthly income, media in the house, heard about STDs, and source of their information.

Part B: It was developed by the researchers based on literature review and guided by Anderson, Saverio et al. and LeFevre. ${ }^{[15-17]}$ This included questions regarding student's knowledge about STDs as definition, causes, types, mode of transmission, vertical transmission, effect on pregnancy outcome, clinical manifestations for male and female, complications of STDs, treatment, role of the family and community to prevent STDs, and finally actions taken for infected sexual partner.

Scoring system for knowledge part: A complete correct answer was scored 2, an incomplete correct answer was scored 1 and an incorrect answer or don't know was scored zero. For each area of knowledge, the scores of items were summed up and divided by the number of items, the total score of knowledge was 56 points. Evaluation of student's knowledge 75\% or more was considered good, level of knowledge, $50-<75 \%$ considered fair, and less than $50 \%$ considered poor.

Tool (II): This was a self-administered questionnaire guided by Stoskopf $\&$ Fageeh $^{[2,18]}$ and modified by the researchers was used to assess student's attitudes toward STDs. The total number of questions measuring attitudes was 19 questions. They had three responses as: agree, not sure and disagree, which were scored as 3,2 and 1, respectively. The total score ranged from 19 to 57 . The total score for each student was divided by the total maximum score and multiplied by 100 to get the percentage of total score, and classified as: Negative if $<75 \%$ and Positive if $\geq 75 \%$ based on statistically analysis.

\subsection{Tools validity and reliability}

The validity of data collection tools and educational session's booklet were tested by a panel of 5 expertise (2 Professors from the Community Health Nursing, 2 Professors from Obstetric and Gynecological Nursing specialties, Faculty of Nursing, Zagazig University, and one Professors expert from Faculty of Medicine) to assess clarity, relevance, application, comprehension, and understanding of the tools, all recommended modifications on the tools were done. Reliability 
of the proposed tools was done by Cronbach's Alpha test; it was 0.979 for tool (I) and 0.980 for tool (II).

\subsection{Ethical considerations}

Subject of the proposed research was approved by the Research Ethics Committee of the Faculty of Nursing at Zagazig University. Official permissions were granted from the directors of the pre mentioned settings. All research ethics issues were taken into consideration during all phases of the study. Each student and his/her parent were informed about the purpose of the study then a written consent was obtained before starting the data collection. Confidentiality was ensured throughout the study process, and the students were assured that all data will be used only for research purpose. Each student was informed that participation is voluntary and he/she was allowed to withdraw from the study at any stage without giving any reason.

\subsection{Pilot study}

Before conducting the main study, a pilot study was carried out on $10 \%$ of the study sample of 37 students who were excluded from the main study sample. The purpose of pilot study was to test the questions for any ambiguity, inapplicability, and feasibility of the tools; accordingly the necessary modifications were done. It also helped the researchers to determine the time needed for filling in the forms.

\subsection{Procedure}

Data collection took a period of six months; from beginning October 2016 to end of March 2017. The researchers started the data collection for 3 days per week from 9.00 AM to 12.00 PM during the 6 months. The execution of the study was through four phases: assessment, planning, implementation, and evaluation.

\subsubsection{Assessment phase}

This phase involved the pre-intervention data collection for baseline assessment. The researchers first introduced themselves and explained the purpose of the research briefly to the school's Director and the staff working in the school. The Headmaster of the school nominated a teacher to assist and facilitate the administration of the questionnaires. The teacher served primarily as a guide and helped in gaining access to students in class and ensuring that the research team did not obstruct normal student activities, as well as seeking permission from other teachers and staff encountered during the data collection.

All the students were met and their verbal agreements for participation were obtained. The researchers distributed the questionnaire to the students and answered for any quieries. The pretest knowledge questionnaire was distributed and self- administered by the students themselves, and then the same questionnaire was used after the session's implementation for post assessment (post-test). The time consumed for answering the study questionnaire ranged from 35-45 minutes. The data were preliminarily analyzed to provide the basis for designing of the intervention sessions.

\subsubsection{Planning phase}

Based on review of literature, sample features and the results obtained from the assessment phase, the researchers designed the intervention sessions and sessions' content. Educational sessions were prepared by the researchers and their contents were validated by a panel of expertises and then distributed to students to be used as a guide for self-learning. The sessions were conducted in Arabic language to be easily understood.

General objective: The general objective of the educational sessions was to upgrade students' knowledge and attitudes towards STDs.

Specific objectives: By the end of the sessions, the students should be able to:

- Identify the definition of STDs and list its types.

- Recognize the causes and list modes of transmission of STDs.

- Be aware of the symptoms and complications of STDs.

- Identify ways of prevention.

- Describe the role of the community and family.

\subsubsection{Implementation phase}

The intervention was performed in the form of sessions; they were implemented in the lab and library of the school. To ensure exposure of all students to the same learning experience, all of them received the same content using same training methods. The educational training methods were lectures, group discussions and brain storming. The sessions were aided by using videos, pictures and posters through laptop to facilitate and illustrate teaching. To ensure that the students understand the content, each session was started by a summary about what was given through the previous session, followed by the objectives of the new one. The intervention was implemented in 8 sessions; the duration of each session was 35-45 minutes for each school at the previously mentioned settings, the total time of sessions was 6-8 hours. The number of students in each session was 25-30 students in order to facilitate learning process and allow each student to participate as well as ensure adequate supervision. The objectives of the sessions were as follows:

At the beginning of the first session an orientation to the educational sessions such as: the rationale, importance of the subject, contents, time and location were elaborated in order to establish good communication. The objective of the 
second session was the explanation about basic knowledge regarding STDs as definition, types and their causative organisms and the modes of their transmission, while the third to sixth sessions were focused on the most important types of STDs as syphilis, chlamydia, gonorrhea, AIDS, HPV and HSV as their clinical manifestations, treatment, complications and prevention of each disease. The 7 th session was focused on the role of the family and community in the prevention of STDs. The last session was to evaluate the effect of the sessions on students' knowledge and attitudes.

\subsubsection{Evaluation phase}

Evaluation of the health educational sessions was done immediately after its implementation, and a follow-up evaluation after three months through applying the same tools of the pretest.

\subsection{Statistical analysis}

The collected data were organized, tabulated and statistically analyzed using the Statistical Package for Social Sciences (SPSS) version 19, created by IBM, Illinois, Chicago, USA. For numerical values the range, mean and standard deviation were calculated. The differences between two mean values were calculated using student's $t$-test. For categorical variable the number and percentage were calculated and differences between observations before, after and at follow up were tested using Friedman Chi square test. On the other hand the difference between only two observations were tested using Wilcoxon Signed rank test. The correlation between two variables was calculated using Pearson's correlation coefficient. The level of significance was adopted at $p<.05$.

\section{Results}

Table 1 shows that $55.9 \%$ of the studied students their age was 16 years with a mean age of $15.83 \pm 0.64$ years and $82.3 \%$ of them were living in urban areas. Additionally, $35.4 \%$ of the studied students their birth order ranked the first birth. Concerning the educational level of students' parents, $61.3 \%$ of their fathers and $51.8 \%$ of their mothers had university education with $66.2 \%$ had sufficient and saving income.

Figure 1 illustrates that $25.6 \%$ of the studied students had information about STDs from lessons in biology as the most common source of information, followed by internet in $12.0 \%$ and $46.3 \%$ didn't have any information.

Table 2 portrays that, only $4.4 \%$ of the studied students identified the methods of STDs transmission at pre sessions compared to $97.0 \%$ and $86.1 \%$ at post and follow up respectively. A considerable change was noticed between studied sample pre, post and follow up sessions implementation related to clinical manifestation among males and females $\left(\chi^{2}=674.1\right.$ $\& 985.7$ respectively at $p=.001)$. Additionally, most of them (95.9\% and $95.6 \%$ ) identified complications that may be arisen from STDs at post and follow up intervention respectively. All the differences observed were highly statistically significant $(p=.001)$.

Table 1. Distribution of the studied students according to their socio-demographic characteristics $(n=367)$

\begin{tabular}{|c|c|c|}
\hline Variables & $\mathbf{N}$ & $\%$ \\
\hline \multicolumn{3}{|l|}{ Age (in years) } \\
\hline $15-$ & 112 & 30.5 \\
\hline $16-$ & 205 & 55.9 \\
\hline 17 & 50 & 13.6 \\
\hline Mean \pm SD & $15.83 \pm 0.64$ & \\
\hline \multicolumn{3}{|l|}{ Gender } \\
\hline Boys & 167 & 45.5 \\
\hline Girls & 200 & 54.5 \\
\hline \multicolumn{3}{|l|}{ Residence } \\
\hline Rural & 65 & 17.7 \\
\hline Urban & 302 & 82.3 \\
\hline \multicolumn{3}{|l|}{ Number of siblings } \\
\hline $1-2$ & 101 & 27.6 \\
\hline $3-4$ & 235 & 64.0 \\
\hline$\geq 5$ & 31 & 8.4 \\
\hline \multicolumn{3}{|l|}{ Birth order } \\
\hline 1 & 130 & 35.4 \\
\hline 2 & 117 & 31.9 \\
\hline 3 & 67 & 18.3 \\
\hline 4 & 38 & 10.4 \\
\hline$\geq 5$ & 15 & 4.0 \\
\hline \multicolumn{3}{|c|}{ Fathers' educational level } \\
\hline Illiterate & 21 & 5.7 \\
\hline Primary & 16 & 4.4 \\
\hline Secondary & 105 & 28.6 \\
\hline University & 225 & 61.3 \\
\hline \multicolumn{3}{|l|}{ Fathers' job } \\
\hline Farmer & 10 & 2.7 \\
\hline Employee & 241 & 65.7 \\
\hline Manual work & 13 & 3.5 \\
\hline Private business & 103 & 28.1 \\
\hline \multicolumn{3}{|c|}{ Mothers' educational level } \\
\hline Illiterate & 31 & 8.4 \\
\hline Primary & 21 & 5.7 \\
\hline Secondary & 125 & 34.1 \\
\hline University & 190 & 51.8 \\
\hline \multicolumn{3}{|l|}{ Mothers' job } \\
\hline Housewife & 208 & 56.7 \\
\hline Working & 159 & 43.3 \\
\hline \multicolumn{3}{|l|}{ Crowding index } \\
\hline$<2$ & 268 & 73.0 \\
\hline$>2$ & 99 & 27.0 \\
\hline \multicolumn{3}{|l|}{ Family income } \\
\hline Sufficient and saving & 243 & 66.2 \\
\hline Just sufficient & 114 & 31.1 \\
\hline Insufficient & 10 & 2.7 \\
\hline
\end{tabular}




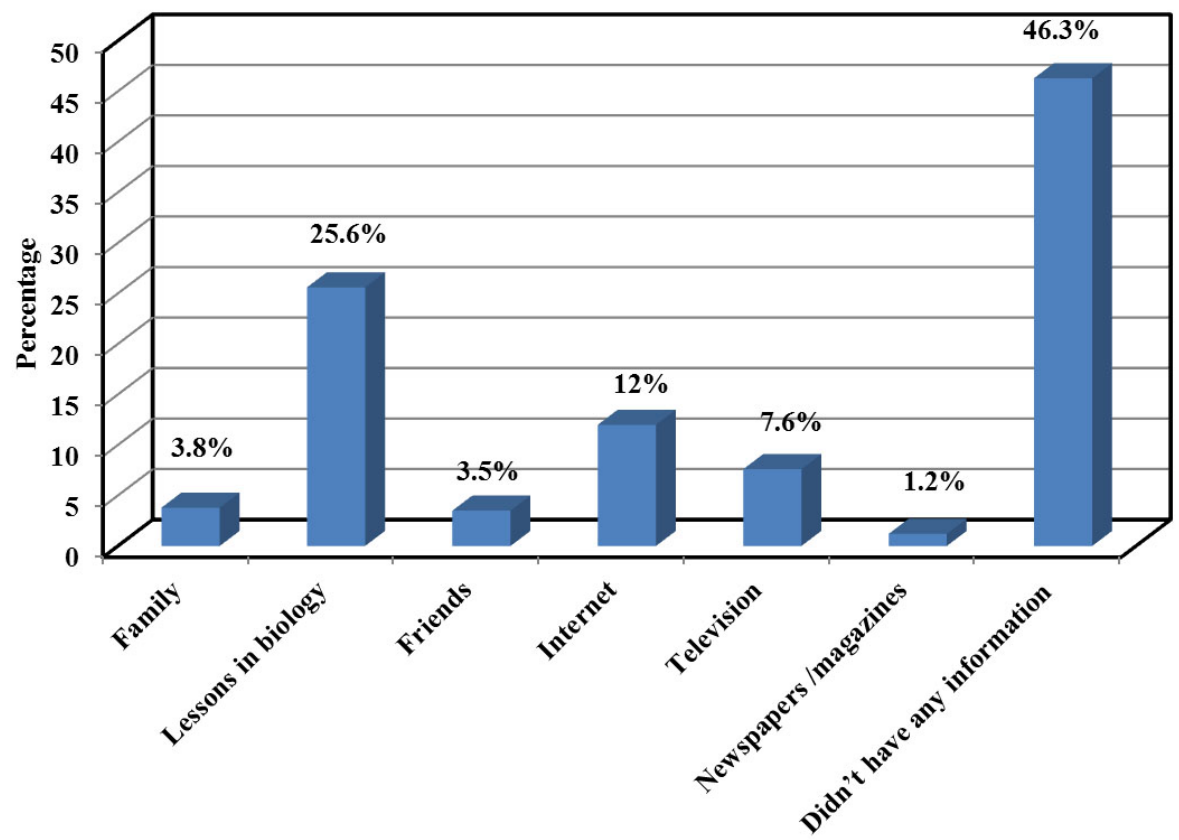

Figure 1. Distribution of studied students according to their source of information about sexually transmitted diseases $(\mathrm{n}=$ 367)

Table 2. Distribution of studied students according to their knowledge about sexually transmitted diseases throughout the intervention phases $(\mathrm{n}=367)$

\begin{tabular}{|c|c|c|c|c|c|c|c|c|}
\hline \multirow{3}{*}{ Variables } & \multicolumn{6}{|c|}{ Correct Answers } & \multirow{3}{*}{$\chi^{2}$} & \multirow{3}{*}{$p$} \\
\hline & \multicolumn{2}{|c|}{ Before } & \multicolumn{2}{|c|}{ After } & \multicolumn{2}{|c|}{ Follow up } & & \\
\hline & No & $\%$ & No & $\%$ & No & $\%$ & & \\
\hline Definition of sexually transmitted diseases & 197 & 53.7 & 362 & 98.6 & 349 & 95.1 & 224.36 & $.001 * * *$ \\
\hline Causative organisms & 46 & 12.5 & 354 & 96.5 & 322 & 87.7 & 583.7 & $.001 * * *$ \\
\hline Knowing types of sexually transmitted diseases & 43 & 11.7 & 359 & 97.8 & 314 & 85.6 & 579.7 & $.001 * * *$ \\
\hline Methods of transmission & 16 & 4.4 & 356 & 97.0 & 316 & 86.1 & 649.1 & $.001 * * *$ \\
\hline Vertical transmission & 170 & 46.3 & 365 & 99.5 & 363 & 98.9 & 380.2 & $.001 * * *$ \\
\hline Methods of vertical transmission & 36 & 9.8 & 358 & 97.5 & 355 & 96.7 & 638.2 & $.001 * * *$ \\
\hline Methods that don't transmit STDs & 5 & 1.4 & 354 & 96.5 & 318 & 86.6 & 675.7 & $.001 * * *$ \\
\hline Manifestations among males & 13 & 3.5 & 350 & 95.4 & 333 & 90.7 & 674.1 & $.001 * * *$ \\
\hline Manifestations among females & 8 & 2.2 & 348 & 94.8 & 325 & 88.6 & 985.7 & $.001 * * *$ \\
\hline Methods of prevention & 10 & 2.7 & 361 & 98.4 & 321 & 87.5 & 681.2 & $.001 * * *$ \\
\hline Complications of STDs & 71 & 19.3 & 352 & 95.9 & 351 & 95.6 & 558.6 & $.001 * * *$ \\
\hline Effect in pregnancy outcome & 11 & 3.0 & 353 & 96.2 & 337 & 91.8 & 684.3 & $.001 * * *$ \\
\hline Available treatment & 164 & 44.7 & 365 & 99.5 & 358 & 97.5 & 373.6 & $.001 * * *$ \\
\hline Specialized referral physician for STIs & 48 & 13.1 & 357 & 97.3 & 318 & 86.6 & 550.7 & $.001 * * *$ \\
\hline Family role to prevent STIs & 13 & 3.5 & 336 & 91.6 & 326 & 88.8 & 680.8 & $.001 * * *$ \\
\hline Community role to prevent STIs & 22 & 6.0 & 346 & 94.3 & 335 & 91.3 & 655.6 & $.001 * * *$ \\
\hline
\end{tabular}

Note. AIDs the only type of STDs known by students; *** $p \leq .001$

Table 3 indicates that, the most chosen action for infected sexual partner according to students' opinion was don't know $(54.5 \%)$ at pre sessions, which changed to $3.5 \%$ and $3.3 \%$ at post and follow up sessions respectively, while asking Published by Sciedu Press for medical examination and treatment was the most chosen action at post sessions in $34.6 \%$, while ask for divorce was present in only $10.2 \%$ in pre sessions which slightly decreased to $7.9 \%$ and $9.5 \%$ at post and follow up respectively. 
Table 3. Distribution of the studied students' opinion according to their reported actions for infected sexual partner $(\mathrm{n}=$ 367)

\begin{tabular}{|c|c|c|c|c|c|c|}
\hline \multirow{2}{*}{ Actions } & \multicolumn{2}{|c|}{ Before } & \multicolumn{2}{|c|}{ After } & \multicolumn{2}{|c|}{ Follow up } \\
\hline & No & $\%$ & No & $\%$ & No & $\%$ \\
\hline Don't know & 200 & 54.5 & 11 & 3.5 & 12 & 3.3 \\
\hline Ask for medical examination $\&$ treatment & 71 & 19.3 & 127 & 34.6 & 126 & 34.3 \\
\hline Avoid sex & 28 & 7.6 & 110 & 30.0 & 120 & 32.7 \\
\hline Ask for divorce & 37 & 10.2 & 29 & 7.9 & 35 & 9.5 \\
\hline$\uparrow$ More than one action & 31 & 8.4 & 88 & 24.0 & 74 & 20.2 \\
\hline$\chi^{2}$ & \multicolumn{6}{|c|}{402.558} \\
\hline$p$ & \multicolumn{6}{|c|}{$.001 * * *$} \\
\hline
\end{tabular}

Table 4 clarifies that, there were highly statistically significant differences between students in relation to their attitudes toward sexually transmitted diseases before and after intervention; pre, post and follow up $(p<.001)$.

Figure 2 illustrates that the total knowledge level of the studied students were scored as good by $0.5 \%$ in pre sessions' intervention which improved to $97.8 \%$ and $95.4 \%$ at post and follow up intervention respectively. Meanwhile, $90.5 \%$ had poor knowledge at pre sessions intervention that reduced to $0.8 \%$ and $1.4 \%$ in post and follow up intervention respectively.

The total attitude score of the study students towards sexually transmitted diseases pre and post sessions as Table 5 demonstrates, highly statistically significant improvement was found among students' attitude level after the educational sessions' implementation $(p=.0001)$.

Table 4. Distribution of the students in relation to their attitudes toward sexually transmitted diseases before and after intervention $(\mathrm{n}=367)$

\begin{tabular}{|c|c|c|c|c|c|c|}
\hline \multirow{3}{*}{ Variables } & \multicolumn{4}{|c|}{ Agreement Answers } & \multirow{3}{*}{$Z$} & \multirow{3}{*}{$p$} \\
\hline & \multicolumn{2}{|c|}{ Before } & \multicolumn{2}{|c|}{ After } & & \\
\hline & No & $\%$ & No & $\%$ & & \\
\hline Can protect myself from STIs & 224 & 61.0 & 362 & 98.6 & 11.430 & $.001 * * *$ \\
\hline Condom can protect from STIs & 176 & 48.0 & 11 & 3.0 & 15.638 & $.001 * * *$ \\
\hline Want to know if I'm infected & 214 & 58.3 & 347 & 94.6 & 9.846 & $.001 * * *$ \\
\hline Should know if partner is infected & 269 & 73.3 & 365 & 99.5 & 8.417 & $.001 * * *$ \\
\hline Partner should know if I'm infected & 301 & 82.0 & 364 & 99.2 & 6.876 & $.001 * * *$ \\
\hline Should get information in university education & 226 & 61.6 & 302 & 82.3 & 6.875 & $.001 * * *$ \\
\hline STIs knowledge in school curriculum is not accepted & 155 & 42.2 & 0 & 0.0 & 14.527 & $.001 * * *$ \\
\hline Should not teach information about genital system & 158 & 43.1 & 4 & 1.1 & 13.087 & $.001 * * *$ \\
\hline STIs is common among drug addicts & 172 & 46.9 & 366 & 99.7 & 12.894 & $.001 * * *$ \\
\hline Accept premarital examination & 240 & 65.4 & 367 & 100 & 10.367 & $.001 * * *$ \\
\hline Shy to complain from STIs & 198 & 54.0 & 43 & 11.7 & 13.498 & $.001 * * *$ \\
\hline Sexual education will encourage premarital sexual relations & 119 & 32.4 & 2 & 0.5 & 14.703 & $.001 * * *$ \\
\hline Parents should teach their children sexual education & 130 & 35.4 & 249 & 67.8 & 10.217 & $.001 * * *$ \\
\hline Adolescents need sexual education & 157 & 42.8 & 316 & 86.1 & 11.960 & $.001 * * *$ \\
\hline Easy to ask about sexual health & 132 & 36.0 & 146 & 39.8 & 5.498 & $.001 * * *$ \\
\hline Can get trustful information about sexual health & 271 & 73.8 & 363 & 98.9 & 8.594 & $.001 * * *$ \\
\hline Have enough sexual information & 153 & 41.7 & 367 & 100 & 13.119 & $.001 * * *$ \\
\hline Interested to get more information about sexual health & 251 & 68.4 & 367 & 100 & 9.754 & $.001 * * *$ \\
\hline Will attend training about sexual health & 209 & 56.9 & 367 & 100 & 11.602 & $.001 * * *$ \\
\hline
\end{tabular}




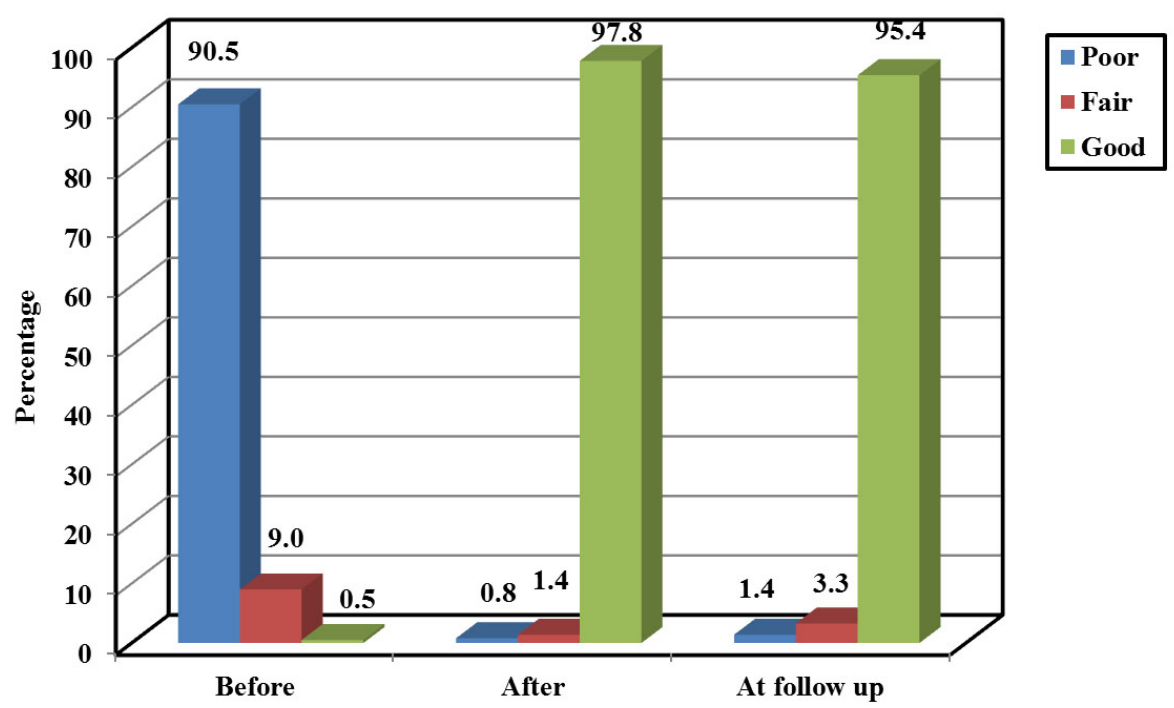

Figure 2. Distribution of students in relation to their level of knowledge score through educational phases $(n=367)$

Table 5. Distribution of the studied students according to their total attitude score throughout educational phases $(\mathrm{n}=$ 367)

\begin{tabular}{llllll}
\hline \multirow{2}{*}{ Attitude } & \multicolumn{2}{l}{ Before } & & & After \\
\cline { 2 - 3 } \cline { 5 - 5 } \cline { 5 - 5 } & No & \% & & No & $\%$ \\
\hline Negative & 134 & 36.5 & & 0 & 0.0 \\
Positive & 233 & 63.5 & & 367 & 100.0 \\
Range & $53-96$ & & & $81-95$ & \\
Mean \pm SD & $77.91 \pm 8.94$ & & $90.80 \pm 2.29$ & \\
$t$ & 27.544 & & & \\
$p$ & $.001 * * *$ & & & \\
\hline$* * * p \leq .001$ & & &
\end{tabular}

Table 6 shows that there were positive correlations between total knowledge score with the students' age and mothers' educational level ( $p=.001 \& .014$ respectively). However, there were no statistically significant correlations between total attitude score and the same items students' age and mothers' educational level of the studied students ( $p=.724$ \& .336 respectively).

Regarding to the total mean score of knowledge in relation to gender and residence of the study students, Table 7 demonstrates that, the total mean knowledge level score was higher in boys than girls (Mean $\pm \mathrm{SD}=22.14 \pm 20.59$ and 20.07 \pm 19.07 respectively) in pre sessions, while it was raised in girls than boys after intervention $(98.91 \pm 6.74$ and 96.76 \pm 8.68 respectively). Additionally, the total mean of knowledge level score was lower in rural areas than urban areas at pre sessions $(10.08 \pm 16.71$ and $23.36 \pm 19.62$ respectively), which raised in urban than rural areas after sessions' intervention and all the differences observed for gender and residence were highly statistically significant $(p=.001)$.

Table 6. Correlations between total knowledge and attitude score in relation to students' socio-demographic characteristics $(\mathrm{n}=367)$

\begin{tabular}{|c|c|c|c|c|}
\hline \multirow{2}{*}{ Variables } & \multicolumn{2}{|c|}{ Knowledge } & \multicolumn{2}{|c|}{ Attitudes } \\
\hline & $r$ & $p$ & $r$ & $p$ \\
\hline Age (in years) & 0.174 & $.001 *$ & 0.018 & .724 \\
\hline Number of siblings & 0.005 & .921 & -0.035 & .500 \\
\hline Birth order & -0.041 & .433 & -0.092 & .077 \\
\hline Fathers' educational level & 0.043 & .417 & 0.025 & .631 \\
\hline Mothers' educational level & 0.128 & $.014^{*}$ & 0.050 & .336 \\
\hline
\end{tabular}
$* p<.05$

Concerning total score level of attitude in relation to gender and residence of the study students, Table 8 indicates that statistically significant positive correlations were found be- tween attitude scores of studied students with their gender and residence where $p=.001$. 
Table 7. Relation of total mean score of knowledge levels in relation to gender and residence of the study subjects $(\mathrm{n}=367)$

\begin{tabular}{|c|c|c|c|c|}
\hline Variables & Total Knowledge Before & Total Knowledge After & $t$ & $p$ \\
\hline \multicolumn{5}{|l|}{ Gender } \\
\hline Boys & $22.14 \pm 20.59$ & $96.76 \pm 8.68$ & 44.766 & $.001^{*}$ \\
\hline Girls & $20.07 \pm 19.07$ & $98.91 \pm 6.74$ & 53.994 & $.001^{*}$ \\
\hline$T^{*}$ & 0.997 & 2.618 & & \\
\hline$p$ & .320 & $.009 *$ & & \\
\hline \multicolumn{5}{|l|}{ Residence } \\
\hline Rural & $10.08 \pm 16.71$ & $98.30 \pm 5.91$ & 41.154 & $.001^{*}$ \\
\hline Urban & $23.36 \pm 19.62$ & $97.85 \pm 8.09$ & 61.281 & $.001^{*}$ \\
\hline T\# & 5.628 & 0.424 & & \\
\hline$p$ & $.001^{*}$ & .672 & & \\
\hline
\end{tabular}

Note. $T^{*}$ Significant difference between boys and girls before and after intervention; $t$ significant difference between knowledge before and after; $T \#$ difference between urban and rural before and after intervention.

Table 8. Relation between total score level of attitude in relation to gender and residence of the study subjects $(\mathrm{n}=367)$

\begin{tabular}{lllll}
\hline Variables & Total Attitude Before & Total Attitude After & $\boldsymbol{t}$ & $\boldsymbol{p}$ \\
\hline Gender & & & & \\
Boys & $81.54 \pm 7.96$ & $91.67 \pm 1.81$ & 16.151 & $.001^{*}$ \\
Girls & $74.87 \pm 8.59$ & $90.07 \pm 2.39$ & 23.838 & $.001^{*}$ \\
$t$ & 7.665 & 7.282 & & \\
$p$ & $0.001^{*}$ & $0.001^{*}$ & & \\
Residence & & & & \\
$\quad$ Rural & $75.79 \pm 8.53$ & $91.50 \pm 1.94$ & 14.741 & $.001^{*}$ \\
Urban & $78.36 \pm 8.97$ & $90.65 \pm 2.33$ & 23.873 & $.001^{*}$ \\
$t$ & 2.114 & 3.086 & & \\
$p$ & $.035^{*}$ & $.001^{*}$ & & \\
\hline${ }^{*} p<.05$ & & & &
\end{tabular}

\section{Discussion}

Adolescence refers to a long transitional, developmental period between childhood and adulthood, and to a maturational process involving major physical, psychological, cognitive and social transformation. The onset of it is marked by puberty, which is primarily a physical, maturational, hormonal and growth process. One in every 5 people in the world is an adolescent, and out of 1.2 billion adolescents worldwide about $85 \%$ lives in developing countries and the remainder in the industrialized world. However, adolescent health, especially STDs is a neglected area Lake. ${ }^{[19]}$ Furthermore, Egyptian girls reach puberty with little information about sexuality and reproduction. Additionally the problem with STDs is that they can occur symptom-free and can thus be passed on unaware during unprotected sexual intercourse. Untreated STDs can lead to serious long-term health consequences, especially for adolescent girls and young women CDC. ${ }^{[10]}$

One of the main objectives of the current study was the as- sessment of students' knowledge about STDs. The overall knowledge score in pre sessions among students regarding the STDs, was very low. This study finding highlighted the urgent need for implementing STDs intervention where knowledge often comes from educational sessions, especially that the prevention and control of STDs among the adolescents, is a low priority for most countries.

The current study revealed that slightly more than half of students heard of the STDs especially HIV/AIDS, and the most common sources of information on STDs mentioned by the students were the school biology lessons. Adolescents lack information on other infections such as: Chlamydia, syphilis, and HPV. This study result was in agreement with Mikolajczyk \& Glaeske, ${ }^{[20]}$ in USA who found that more than $90 \%$ of adolescents heard of STDs especially HIV/AIDS and the most common source of their information on sexuality and STIs was the school (biology lessons). This might be due to that the highest awareness and knowledge were reported for HIV/AIDS. This is certainly linked to the fact that since 
the mid-1980s, extensive awareness campaigns on this topic have been conducted globally. Similarly, Zeeb et al., ${ }^{[21]}$ in a study in Germany showed that the source information on sexual issues commonly cited by the students were biology lessons $(78 \%)$. This study result was in contrast with that of a study done in Saudi Arabia by Fageeh ${ }^{[2]}$ who reported that the major sources from which the respondents received information were internet $(375,87 \%)$, books $(356,73 \%)$ and TV/radio $(302,62 \%)$. The contradiction with this study might be due to differences of location and culture.

In the present study, all the students owned computers and had internet access at home. However, only less than one eighth gained information regarding STDs by internet. This result was incongruent with that of Bleakley et al., ${ }^{[22]}$ who mentioned that the internet and media sources have become a convenient way of accessing information on any topic. However, they may lack the explanations needed to understand them, and at times prove to be harmful rather than beneficial for young adolescents.

After implementation of the health educational intervention, the research objective and hypothesis of the present study were highly achieved since the results pointed to generally higher level scores of knowledge and attitudes of STDs. From the researchers' point of view, these improvements might be due to the effect of the training sessions, which were given to adolescents. In addition, they were enthusiast to participate in the sessions and willing to attend future educational sessions. Therefore, these sessions have been successful in the students' improvement of knowledge and attitudes of STDs.

The current study finding was in agreement with that of Amu \& Adegun ${ }^{[23]}$ in Nigeria, who conducted a study to assess awareness and knowledge of sexually transmitted infections among secondary school adolescents and found that nearly all of the respondents had good knowledge related to STDs. This finding is consistent with that of a study carried out in Malaysia, by Awang et al. ${ }^{[24]}$ who mentioned that $92 \%$ of the adolescents reported awareness of STDs. On the same context, Aliyu et al. ${ }^{[25]}$ who conducted a study in Northern Nigeria, reported that $67 \%$ of adolescents had satisfactory knowledge of STDs. From the researcher's point of view, these improvements might be due to the effect of the educational sessions which was given to adolescents. In addition, they were enthusiast to participate in the sessions, which answered to their queries and concerns about STDs, so they showed desire and willing to attend future educational sessions. Therefore, these sessions have been successful in the students' improvement of knowledge and attitudes about STDs.
As regards follow up knowledge after 3 months, the present study finding revealed a slight decrease in students' knowledge. The researchers stress that the sessions should be repeated after a certain interval to upgrade their knowledge and maintain their achievement. This could be in the form of equipping them with booklet, workshops and boosting their knowledge regularly.

As for attitude, the present study result showed that there were statistically significant positive attitudes toward all areas of STDs throughout intervention phases, where improvements between pretest and posttest intervention were obvious. This finding may be attributed to the health educational sessions which played a significant role on improving attitude scores among students. Furthermore, the higher attitude scores among the students in higher level of education could be attributed to the maturation of the students who consequently acquired more knowledge. In confirmation for this explanation, the study findings demonstrated a significant positive correlation between students' scores of knowledge and attitudes. A similar positive correlation between adolescents' knowledge and attitude was reported by Chueh et al. ${ }^{[26]}$ in China.

Considering students' opinion according to their reported action toward the infected sexual partner, comparison between pre- post interventions reveled that a minority claimed that they would ask for a divorce, which decreased at posttests. This reflects that awareness about prevention made them dealing with the problem adding to the rejection of the society of this behavior, which in turn demarcates the necessity of awareness and prevention. This finding contrast with that of a study conducted in Saudi Arabia by Fageeh ${ }^{[2]}$ who mentioned that $40 \%$ of the participants claimed they would ask for a divorce if their partner had a STD.

Concerning students' age, which ranged between 15 and 17 years, with a mean of $15.83 \pm 0.64$, representing middle periods of adolescence. This indicates the importance of the selection of this age group in the present study. In this regard, Igras et al. ${ }^{[27]}$ noted that most interventions focus on middle adolescents, overlooking early adolescence, which marks a critical transition between childhood and adulthood. Moreover, at this stage, adolescents start to have queries and concerns regarding their puberty and all related issues. The study results were supported by the Centers for Disease Control and Prevention (CDC) estimates that there are approximately 20 million new STD infections each year almost half of them among young people ages 15 to 24 Satterwhite. ${ }^{[28]}$ In line with the previous findings, Agyekum \& Suapim ${ }^{[29]}$ in a study in Ghana, showed that more than two thirds (70.4\%) of the students were between the ages of 16 and 19 years 
old. So, they recommended that primary prevention of STDs needs to be given high priority and education; moreover, it should be addressed early in schools to encourage premarital screenings.

The present study results also demonstrated significant relations between students' knowledge and some of the family socio-demographic and economic characteristics. Thus, knowledge was higher among students and positively correlated to the levels of their fathers' and mothers' education. Thus, the overall favorable socio-economic factors would mediate a better level of knowledge about STDs among adolescents, since parents' education is an important factor in transferring related sound information to their children. In agreement with this study result by Alquaiz et al. ${ }^{[30]}$ in Saudi Arabia demonstrated that adolescent girls' knowledge of STDs was positively influenced by higher levels of parents' education.

\section{Conclusion}

The study revealed that the educational sessions were effective in increasing the level of students' knowledge as well as acquiring positive attitudes toward STDs prevention.

\section{Recommendations}

On the basis of the current study findings, the following recommendations were suggested:

- Primary prevention of STDs needs to be given high priority and education about it should be presented early in schools to encourage premarital screenings.

- Health educational and training sessions about STDs should be provided to all students in the schools with illustrated booklets for maintaining knowledge of its most important types. Furthermore, media enlightenment campaigns about these diseases should also be emphasized.

- Further research should be geared towards implementing different educational interventions to improve adolescents' knowledge and attitudes about STDs and testing their effectiveness.

\section{CONFlicts OF InTEREST Disclosure}

The authors declare that there is no conflict of interest.

\section{REFERENCES}

[1] El-Gelany S, Moussa O. Reproductive health awareness among educated young women in Egypt. International Journal of Gynecology and Obstetrics. 2013; 120: 23-26. PMid:23099050 https : //doi.org/10.1016/j.ijgo.2012.07.027

[2] Fageeh W. Awareness of Sexually Transmitted Diseases among Adolescents in Saudi Arabia. JKAU: Med. Sci. 2008; 15(1): 77-90.

[3] UNICEF Egypt: children in Egypt, statistical digest. Chapter 12 youth and adolescent. UNICEF Egypt, United Nations Children's Fund, Egypt. 2015; 1-19 p.

[4] Ray S, Ghosh T, Chandra P, et al. Knowledge and Information on Psychological, Physiological and Gynecological Problems among Adolescent School Girls of Eastern India. Ethiop J Health Sci. 2011; 21(3): 183-189.

[5] Reis N, Kilic D, Engin R, et al. Sexual and Reproductive Health Needs of adolescent girls From Conservative and Low-Income Families in Erzurum, Turkey. Health. 2011; 3(6): 370-377. https: //doi.org/10.4236/health.2011.36063

[6] Visalli G, Picerno I, Vita G, et al. Knowledge of Sexually Transmitted Infections among Youngers of the City of Messina (Sicily). J Prev Med Hyg. 2014; 55: 17-22.

[7] Kimberly A, Workowski M, Gail A, et al. Sexually Transmitted Diseases Treatment Guidelines. Centers for Diseases Control and Prevention, Morbidity and Mortality Weekly Report. Recommendations and Reports. 2015; 64: 3 .

[8] Center for Disease Control' CDC: Sexually Transmitted Diseases. Last updated Sept. 2010.

[9] Adegun P, Solomon O, Adegoke S. Knowledge of Sexually Transmitted Infections among Patients Attending Outpatient Clinics at
University Teaching Hospital. Ado-Ekiti, Nigeria. Journal of Public Health and Epidemiology. 2013; 5(3): 110-114.

[10] Center for Disease Control CDC: Sexually Transmitted Diseases (STDs), Diseases and Related Conditions. 2013.

[11] Amsale C, Yemana B. Knowledge of Sexually Transmitted Infections and Barriers to Seeking Health Services among High School Adolescents in Addis. 2012; 3(5): 2-6.

[12] Fang Y, Chuan P. Aboriginal Nurses' Perception of Facilitators and Barriers for Taking a Sexual History in Taiwan. Public Health Nursing. 2003; 20(4): 281-286. https : //doi.org/10.1046/j.1525 $-1446.2003 .20405 . \mathrm{x}$

[13] Amin T. Sexually Transmitted infections: The Egyptian Situation with Special Emphasis on HIV/AIDS. International Public Health Forum. 2014; 1(3): 6-13.

[14] Selim M, El-Shereef E. Perceptions of Secondary Technical Schools Students in Assiut, Upper Egypt, about AIDS: Effect of an Educational Intervention. J Family Community Med. 2010; 17(1): 3-10. PMid:22022664 https://doi.org/10.4103/1319-1683.6878 2

[15] Anderson C, Gallo M, Kong H, et al. Randomized Controlled Trial on The Effectiveness of Counseling Messages for avoiding Unprotected Sexual Intercourse during Sexually Transmitted Infection and Reproductive Tract Infection Treatment among Female Sexually Transmitted Infection Clinic Patients. Sex Transm Dis. 2013; 40: 105-10. PMid:23321990 https://doi .org/10.1097/OLQ.0b01 3e31827938a1

[16] Saverio C, Dudas S, Bremer M, et al. Sexually Transmitted Infections and Prostate Cancer Risk: A systematic Review and Met analysis. Cancer Epidemiology. 2014; 38(4): 329-338. PMid:24986642 https://doi.org/10.1016/j.canep.2014.06.002 
[17] LeFevre M. Behavioral Counseling Interventions to Prevent Sexually Transmitted Infections. Ann Intern Med. 2014; 161: 894-901. PMid:25244227 https://doi .org/10.7326/M14-1965

[18] Stoskopf A. College Students Knowledge of Sexually Transmitted Diseases. A Research Paper Submitted in Partial Fulfillment of the Requirements for the Master of Science Degree With a Major in Home Economics, Home Economics with a Family Studies and Human Development Concentration. 1999; 1-55 p.

[19] Lake A. The State of The World's Children 2011, Adolescence an Age of Opportunity. United Nations Children's Fund (UNICEF) February. 2011.

[20] Mikolajczyk R. Glaeske G. Assessing Knowledge and Awareness of Sexually Transmitted Infections among School-going Adolescents. Florence Samkange-Zeeb, University of Bremen Faculty of Human and Health Sciences. 2013.

[21] Zeeb F, Mikolajczyk R, Zeeb H. Awareness and Knowledge of Sexually Transmitted Diseases among Secondary School Students in two German Cities. J Community Health. 2013; 38: 293-300. PMid:23001541 https://doi.org/10.1007/s10900-012-961 4-4

[22] Bleakley A, Fishbein M, Jordan A. How Source of Sexual Information Relate to Adolescents Beliefs about Sex. Am J Health Behav. 2009; 33: 37-48. PMid: 18844519

[23] Amu E, Adegun P. Awareness and Knowledge of Sexually Transmitted Infections among Secondary School Adolescents in Ado Ekiti, South Western Nigeria. Journal of Sexually Transmitted Diseases. 2015.
[24] Awang L, Wong R, Low W. Knowledge of Sexually Transmitted Diseases and Sexual Behaviors among Malaysian Male Youths. Journal of Biosocial Science. 2014; 46(2): 214-224. PMid:23480474 https://doi.org/10.1017/S0021932013000114

[25] Aliyu A, Dahiru T, Ladan A, et al. Knowledge, Sources of Information, and Risk Factors for Sexually Transmitted Infections among Secondary School Youth in Zaria, Northern Nigeria. Journal of Medicine in the Tropics. 2013; 2(15): 102-106. https: //doi.org/10.4103/2276-7096.123582

[26] Chueh K, Ding G, Yao K, et al. Relationships among Risk Knowledge, Attitudes and Ability to Resist Substance Abuse in Adolescents. Article in Chinese. Hu Li Za Zhi. 2013: 60(1): 60-8.

[27] Igras S, Macieira M, Murphy E, et al. Investing in very Young Adolescents' Sexual and Reproductive Health. Glob Public Health. 2014; 9(5): 555-69. PMid:24824757 https://doi .org/10.1080/1744 1692.2014 .908230

[28] Satterwhite C. Sexually transmitted infections among U.S. women and men: Prevalence and incidence estimates, 2008. Sex Transm Dis 2013; 40(3): 187-193. PMid:23403598 https://doi.org/10.1 097/OLQ.0b013e318286bb53

[29] Agyekum N, Suapim R. Knowledge and Awareness of HIV/Aids among High School Girls in Ghana. HIV/Aids Research and Palliative Care. 2013; 5: 137-144 .

[30] AlQuaiz A, Kazi A, Al Muneef M. Determinants of Sexual Health Knowledge in Adolescent Girls in Schools of Riyadh-Saudi Arabia: A Cross Sectional Study. BMC Women's Health. 2013; 13: 19. PMid:23587104 https : //doi .org/10.1186/1472-6874-13-1 9 